\title{
Original
}

\section{Immunohistochemical Observations of Changes of Neurons Containing Endogenous Vasodilators Produced by Transient Cerebral Ischemia in the Amygdaloid Complex of the Rat Brain}

\author{
Ken SaSaKi, Hidekatsu Mizushima, Yoshinobu Suzuki, Motohiko Shimazu, \\ Takanobu Iwata, Kiyoshi Matsumoto, Seiji Shiod** \\ and Yasumitsu NAKAI*
}

\begin{abstract}
We analyzed the immunohistology and the quantitative temporal changes of immunotinctable endogenous vasodilators [calcitonin gene-related peptide (CGRP), substance $P$ (SP), vasoactive intestinal polypeptide (VIP)] induced in the rat amygdaloid complex (corpus amygdaloideum) by one-hour cerebral ischemia. Blood levels of these vascular agonists were also measured and compared with the immunohistochemical observation results. The immunotinctability of CGRP immunoreactive fibers decreased significantly $12 \mathrm{~h}$ after cerebral ischemia. CGRP concentration in the blood increased significantly in the 6 to $12 \mathrm{~h}$ after cerebral ischemia, decreased slightly at $24 \mathrm{~h}$, and returned to normal levels at 3 days. The immunotinctability of SP immunopositive fibers decreased significantly $12 \mathrm{~h}$ to $24 \mathrm{~h}$ after cerebral ischemia, recovered slightly at 3 days, and returned to near normal level at 1 week. Blood levels of SP decreased significantly $12 \mathrm{~h}$ after cerebral ischemia and appeared normal at $24 \mathrm{~h}$ and 3 days. No significant changes were observed in the blood levels of VIP nor in the immunotinctability of VIP immunopositive fibers from 3 hours to 2 weeks after cerebral ischemia. Our results suggest that after cerebral ischemia increases CGRP secretion into the blood stream and CGRP synthesis in the amygdaloid complex decreases. SP is synthesized in the amygdaloid complex and its release into the blood stream during the first 12 to $24 \mathrm{~h}$ and does not change the blood levels of VIP in this model. Hence the effects of cerebral ischemia effects on individual vasodilators vary.
\end{abstract}

Key words: cerebral ischemia, immunohistochemistry, vasodilative substances

\section{Introduction}

Nerve cells of the human central nervous system are extremely sensitive to tissue ischemia, but brain glia cells and blood vessels are relatively impervious. Sensitivity of the different nerve cells to ischemia varies by region. Layers 3, 5 and 6 of the cerebral cortex, Sommer's sector of the hippocampus, the granular layer, amygdaloid nucleus, Purkinje's cells, and basket cells of the cerebellum, and portions of the brain stem have been reported to be particularly vulnerable to damage from ischemia ${ }^{1-4}$. In the present study limited ischemia of one side of the middle cerebral artery was produced in rats, and the changes in sensitivity 
of CGRP, SP and VIP, vasodilative substances localized in the amygdaloid complex (corpus amygdaloideum) were immunohistochemically examined, and their blood levels measured. The immunohistochemical results of the normal and ischemic sides were analyzed compared.

\section{Materials and Methods}

The subjects were adult male Wistar rats weighing 250 to $350 \mathrm{~g}$.

\section{Production of Cerebral Ischemia}

The right middle cerebral artery was exposed under a microscope using the Tamura method $^{5,6)}$, and blood flow was halted for $1 \mathrm{~h}$ with a Sugita temporary clip.

After an animal was anesthetized with $30 \mathrm{mg} / \mathrm{kg}$ intraperitoneal phenobarbital, the trachea was intubated and anesthesia was maintained by gas (GOF: fluorothane $0.5-0.25 \%, \mathrm{O}_{2} 33 \%$, $\mathrm{N}_{2} \mathrm{O} 67 \%$ ). The operation, from craniectomy through the placement of the clip, lasted 10 to $15 \mathrm{~min}$. The pulse was monitored and anesthesia was adjusted to maintain a rate of 250-300 beats per min. The obstructed region was located at the intersection of the middle cerebral artery and the olfactory tract, on the proximal side of the branch running parallel and anterior to the olfactory tract. Animals not satisfying these conditions were excluded from the experiment. After arousal, spontaneous respiration was confirmed and the animals were extubated. One hour post-ischemia the animals were observed for neurological symptoms.

In the sham operations, the same procedure was followed from anesthesia to craniectomy and desquamation of the cranial arachnoid, but the clip was not used and the animals were maintained in that condition for one hour. After closure, the animals were aroused and observed for neurological symptoms.

\section{Immunohistochemical Methods}

At 3, 6, 12 and $24 \mathrm{~h}$ and 3, 7 and 14 days post-ischemia, 3 animals from each group were perfused through the left ventricle with $200 \mathrm{ml}$ of a mixture of $4 \%$ paraformaldehyde and $0.4 \%$ glutaraldehyde (0.1 M Millonig's phosphate buffer (PB), $\mathrm{pH} 7.2-7.4)$. Brains were then removed, and coronary tissue blocks were made and fixed in $4 \%$ paraformaldehyde solution. The specimens were rinsed overnight in $0.1 \mathrm{M} \mathrm{PB}$ with $20 \%$ sucrose, and then frozen with liquid nitrogen. Following the Atlas of Paxinos and Watson ${ }^{7)}$, sequential frozen $20 \mu \mathrm{m}$ sections were prepared from the third ventricle to the inferior horn of the lateral ventricle. Every fifth section was selected for evaluation. The sections were incubated for 5 days at $4^{\circ} \mathrm{C}$ in $0.1 \mathrm{M} \mathrm{PB}$ containing $0.2 \%$ Triton $\mathrm{X}-100$, allowed to react with $3 \%$ hydrogen peroxide for $10 \mathrm{~min}$ at room temperature, and then rinsed 3 times for $10 \mathrm{~min}$ each with $0.1 \mathrm{M}$ PB containing $0.2 \%$ Triton X-100. The specimens were then incubated in $5 \%$ normal goat serum (NGS) for $15 \mathrm{~min}$ at room temperature, placed in the antibody suspension of CGRP (Amersham, 1/1,000), SP (Amersham, 1/1,000), or VIP (Amersham, 1/2,000) antibody suspension at room temperature for $2 \mathrm{~h}$, and then in $\mathrm{PB}$ overnight at $4^{\circ} \mathrm{C}$. After rinsing 3 times for $10 \mathrm{~min}$ each with $0.1 \mathrm{M}$ PB containing $0.2 \%$ Triton X-100, they were incubated with goat anti-rabbit IgG (Toyo serum, 1/100) for $1 \mathrm{~h}$ at room temperature, rinsed again 3 times for 10 min each with $0.1 \mathrm{M} \mathrm{PB} 0.2 \%$ Triton $\mathrm{X}-100$, and incubated with a peroxidase-antiperoxidase (PAP) complex (Toyo serum, 1/800) for $1.5 \mathrm{~h}$ at room temperature. The specimens were then placed in a diaminobenzidine (DAB) solution at room temperature for 15-30 min, and placed on a slide. DAB reactive substances were stabilized with osmic acid, and then the specimens were dehydrated with alcohol, and passed through pure xylene. The specimens were then enclosed in Malinole and observed through 
a light microscope.

In the control, instead of the primary antibodies, normal rabbit blood serum was used and the specimens were prepared and immunostained similarly using the PAP technique.

3. Measurements

A high speed image analyzer (SP-500, Olympus) was used to quantitatively measure structural changes in the CGRP, SP and VIP immunopositive regions of the amygdaloid complex that resulted from cerebral ischemia. The immunopositive regions were processed in a two step fashion, and area comparisons per unit area in the measurement regions were measured quantitatively.

\section{Blood Levels}

Cerebral ischemic animals were prepared using the procedure mentioned above, and blood was drawn from the left ventricles of 3 animals each at $6,12,24 \mathrm{~h}$ and 3 days after cerebral ischemia. Blood levels of the individual neuropeptides (CGRP, SP, VIP) were measured using the RIA-DCC method.

\section{Verification}

Immunohistochemical results of the high speed image analyzer (SP-500) were computed and verified as the ratio between the normal side and the ischemic side of the specimen. Blood levels were compared with those in normal animals and verified by $\mathrm{T}$ test.

\section{Results}

Of the animals prepared, 61 that showed signs of slight paralysis, which completely disappeared in 1-2 $\mathrm{h}$ after arousal, were included in this study, but other animals with no symptoms $(\mathrm{N}=7)$, those showing signs of convulsions $(\mathrm{N}=1)$ upon arousal, or those in which left side paralysis which did not disappear $(\mathrm{N}=7)$, were excluded. Seven animals were used to define baseline blood level values of the individual substances. The animals in the sham operated group did not develop any neurological symptoms upon arousal.

Occlusion by coagulation in the middle cerebral artery caused infarction to the inferior temporal lobe, basal ganglia, and amygdaloid complex.

\section{CGRP}

Abundant CGRP immunopositive fibers were found distributed in the amygdaloid complex, especially in the central nuclear area of the cortical medial nuclear group. The immunotinctability of the CGRP positive fibers showed almost no change 6 hours after cerebral ischemia, indicating no effect of the ischemia (Table 1, Figs. 1, 2a, b). However, at $12 \mathrm{~h}$ the immunotinctability declined to $54.7 \%$ of the control side $(\mathrm{p}<0.05)$ (Tables 1 , Figs. $1,2 \mathrm{c})$. By $24 \mathrm{~h}$ it had increased slightly compared to the control side (Table 1, Fig. 1), and by 3 days had returned to normal (Table 1, Figs. 1, 2d). Blood levels of CGRP $6 \mathrm{~h}$ after ischemia

Table 1. Ratios $(100 \times$ ischemic side/control side) of immunotinctabilities of CGRP, SP and VIP. (\%)

\begin{tabular}{lrrrrrrr} 
& $3 \mathrm{~h}$ & $6 \mathrm{~h}$ & $12 \mathrm{~h}$ & $24 \mathrm{~h}$ & 3 days & 1 week & 2 weeks \\
\hline CGRP & 117.1 & 97.5 & $54.7^{* *}$ & 117.7 & 97.2 & 101.9 & 101.1 \\
SP & 78.8 & 100.8 & $47.0^{* *}$ & $45.1^{*}$ & 67.8 & 92.5 & 85.5 \\
VIP & 81.3 & 116.2 & 107.3 & 118.0 & 119.6 & 105.1 & 99.7 \\
\hline
\end{tabular}

${ }^{*} \mathrm{p}<0.01, * * \mathrm{p}<0.05$. 


\section{G R P}

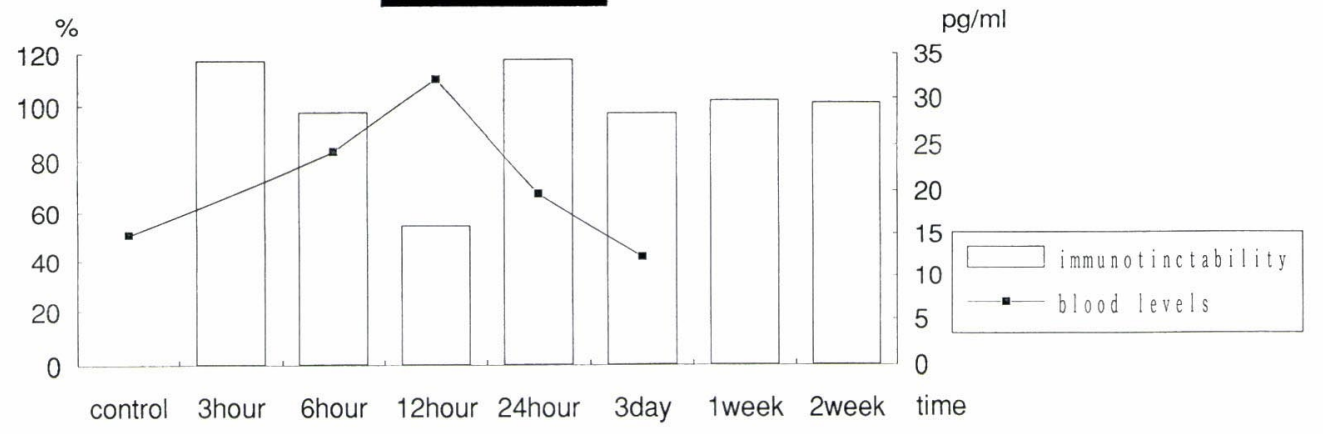

Fig. 1. Time related changes in the tinctabilities and blood levels of the CGRP immunopositive neurons. At $12 \mathrm{~h}$ the tinctability of CGRP was significantly less than that of the control side $(\mathrm{p}<0.05)$. At $6,12(\mathrm{p}<0.01)$ and $24 \mathrm{~h}(\mathrm{p}<0.05)$ the blood level of CGRP was significantly increased.
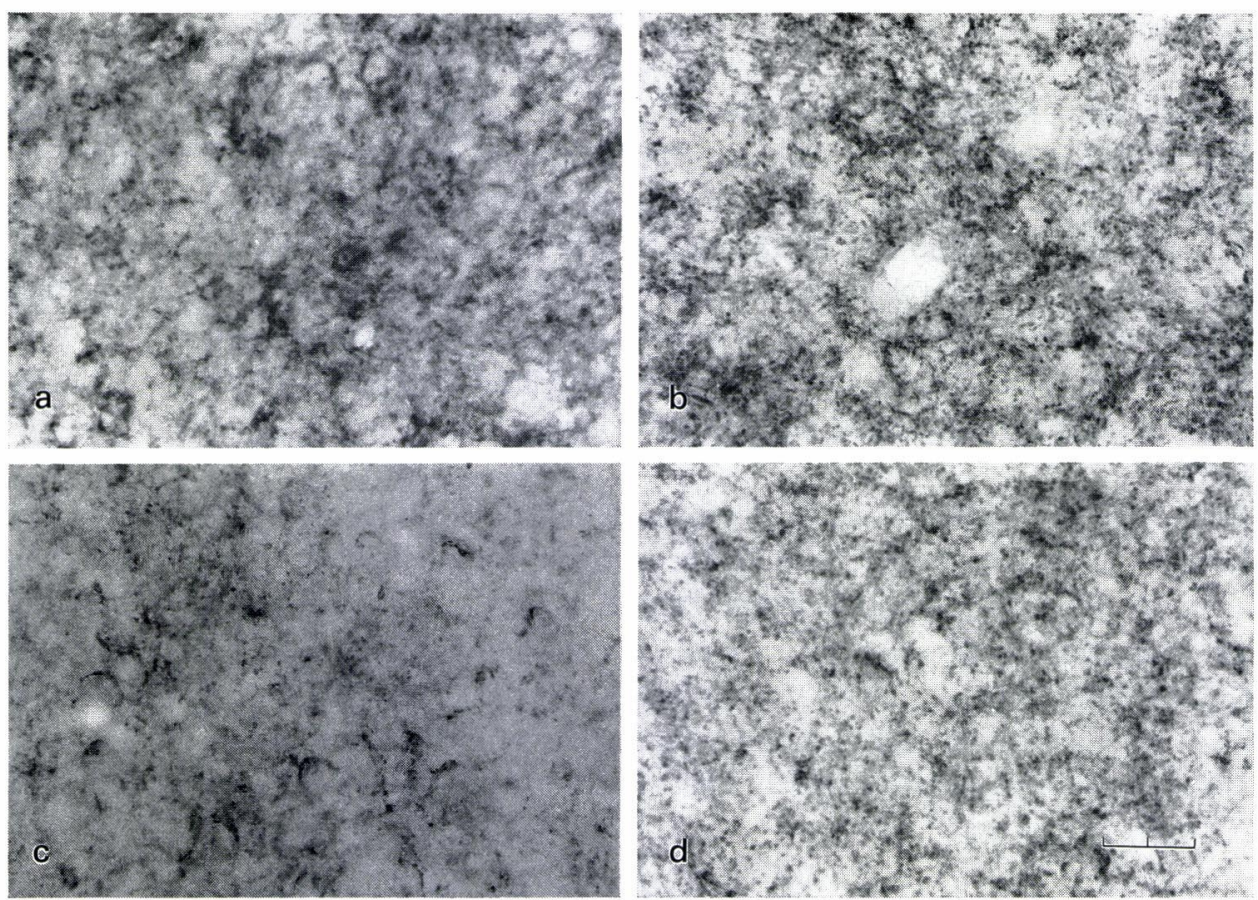

Fig. 2. Light micrographs of CGRP immunostaining. Changes in tinctability of the CGRP immunopositive neurons with time.

(a) $6 \mathrm{~h}$ post ischemia, control side, (b) $6 \mathrm{~h}$ post ischemia, ischemic side, (c) $12 \mathrm{~h}$ post ischemia, ischemic side, and (d) 3 days post ischemia, ischemic side. Scale Bar $=20 \mu \mathrm{m}$. At $6 \mathrm{~h}$ there was no change from the control side; at $12 \mathrm{~h}$ the tinctability of CGRP was significantly decreased $(\mathrm{p}<0.05)$; at $24 \mathrm{~h}$ returned to normal. 
Table 2. Blood levels of CGRP and SP $(\mathrm{pg} / \mathrm{ml})$.

\begin{tabular}{lrrrrr}
\hline & Control & $6 \mathrm{~h}$ & $12 \mathrm{~h}$ & $24 \mathrm{~h}$ & \multicolumn{1}{c}{3 days } \\
\hline CGRP & 14.8 & $24.3^{*}$ & $25.9^{*}$ & $19.7^{* *}$ & 12.2 \\
SP & 144.2 & 127.3 & $82.9^{* *}$ & 101.7 & 104.7 \\
\hline
\end{tabular}

${ }^{*} \mathrm{p}<0.01,{ }^{* *} \mathrm{p}<0.05$.

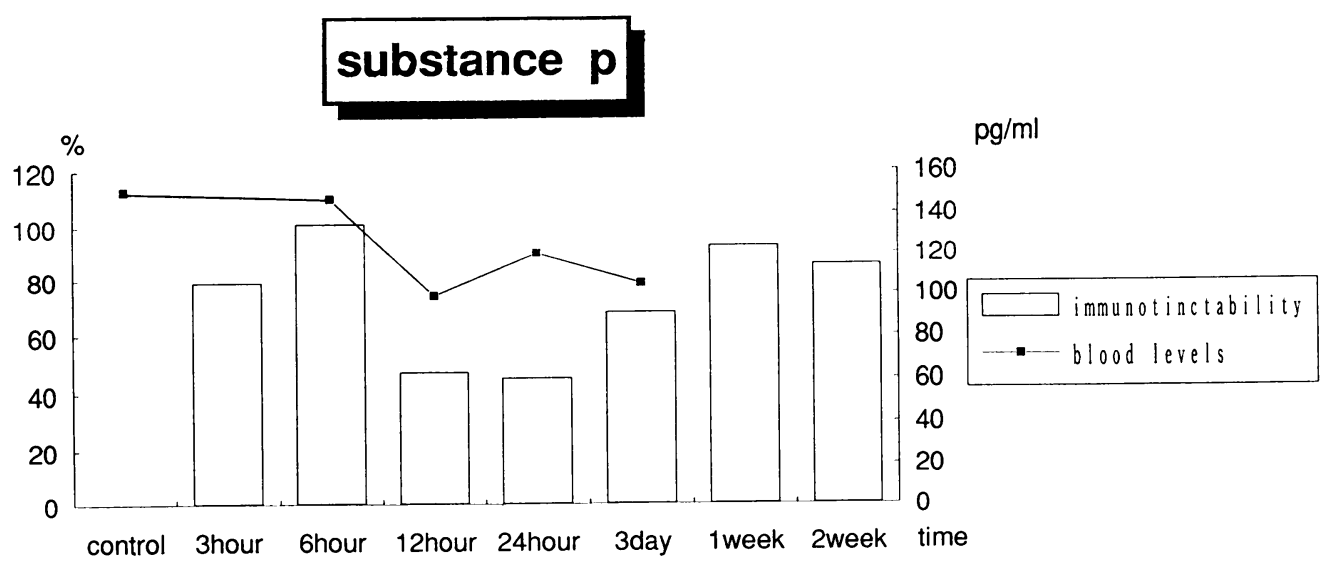

Fig. 3. Changes in the tinctabilities and blood levels of the SP immunopositive neurons with time. At $12 \mathrm{~h}(\mathrm{p}<0.05)$ and $24 \mathrm{~h}(\mathrm{p}<0.01)$ the tinctability of SP was significantly decreased; it returned to normal at 3 days. At $12 \mathrm{~h}$ the blood level of SP was significantly decreased $(\mathrm{p}<0.05)$.

were significantly increased $(\mathrm{p}<0.01)$; this peaked at $12 \mathrm{~h}(\mathrm{p}<0.01)$, and then steadily declined to $24 \mathrm{~h}(\mathrm{p}<0.05)$ and 3 days (Table 2, Fig. 1).

2. $S P$

SP immunopositive fibers were densely distributed in the medial nucleus of the amygdaloid complex, moderately distributed in the central nucleus, and slightly to moderately distributed in other areas of the amygdaloid complex. The immunotinctability of SP immunopositive fibers 12 and $24 \mathrm{~h}$ after ischemia declined to $47.0 \%(\mathrm{p}<0.05)$ and $45.1 \% \quad(\mathrm{p}<0.01)$, respectively compared to that of the control side. It returned to normal at 1 week (Table 1 , Figs. 3, 4). Meanwhile, SP concentrations in the blood declined at $6 \mathrm{~h}$ after ischemia reaching its nadir at $12 \mathrm{~h}$ and rebounding to normal at $24 \mathrm{~h}$ (Table 2).

3. VIP

Many VIP immunopositive fibers were found in the central nucleus of the amygdaloid complex. Both blood concentration of VIP and immunotinctability of VIP immunopositive fibers from $3 \mathrm{~h}$ to 2 weeks after ischemia registered no significant changes (Table 1, Figs. $5,6)$.

\section{Sham Operation}

At identical times, animals from the sham operated group were also prepared and immunohistochemically stained specimens were measured. No significance of variance was found. Consequently, we believe that the effects of anesthesia and surgical manipulaitons can be disregarded. 

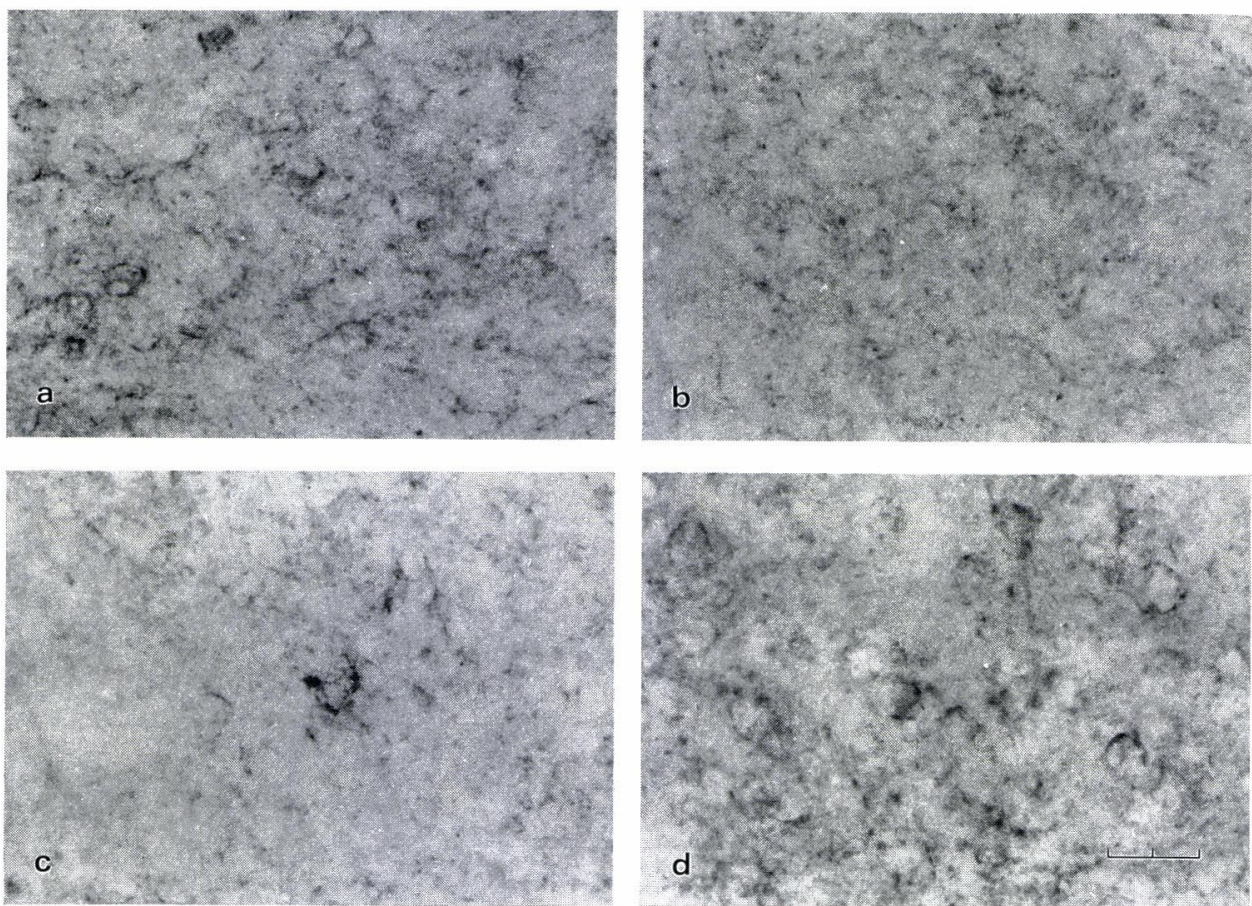

Fig. 4. Light micrographs of SP immunostaining. Changes in the tinctability of the SP immunopositive neurons with time.

(a) $6 \mathrm{~h}$ post ischemia, control side, (b) $6 \mathrm{~h}$ post ischemia, ischemic side, (c) $12 \mathrm{~h}$ post ischemia, inschemic side, and (d) 3 days post ischemia, ischemic side. Scale $\mathrm{Bar}=20 \mu \mathrm{m}$. At $6 \mathrm{~h}$ there was no change from the control side; but at $12 \mathrm{~h}$ the tinctability of SP was significantly decreased $(\mathrm{p}<0.05)$; returned to normal at 3 days.
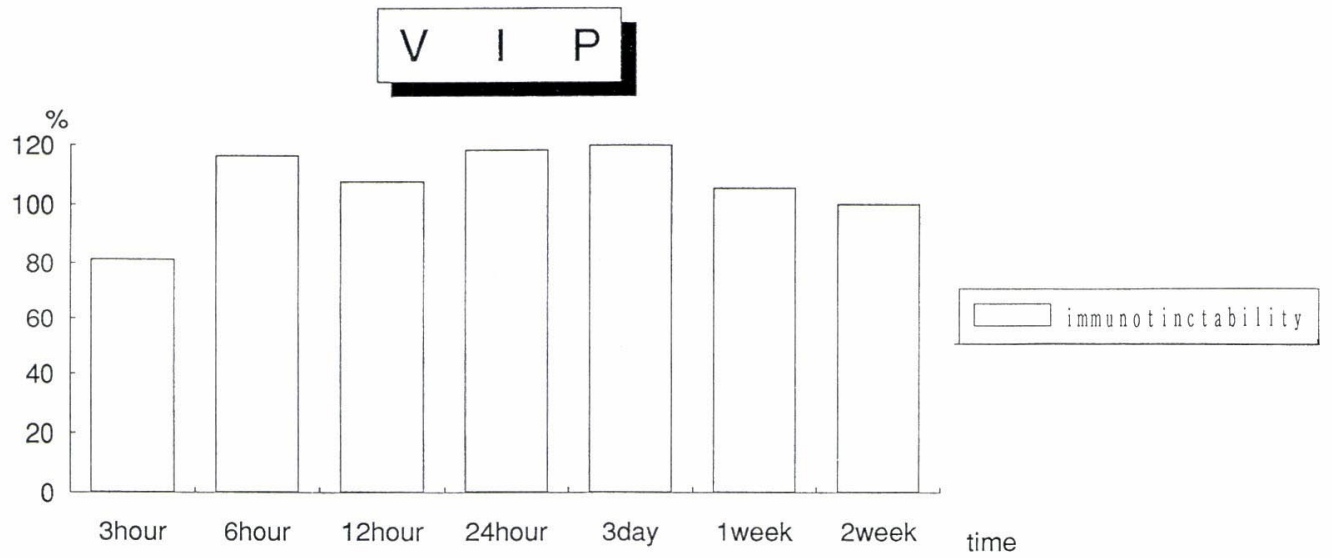

Fig. 5. Changes in the tinctabilities of the VIP immunopositive neurons wiht time. There is no significant difference from the control side. 

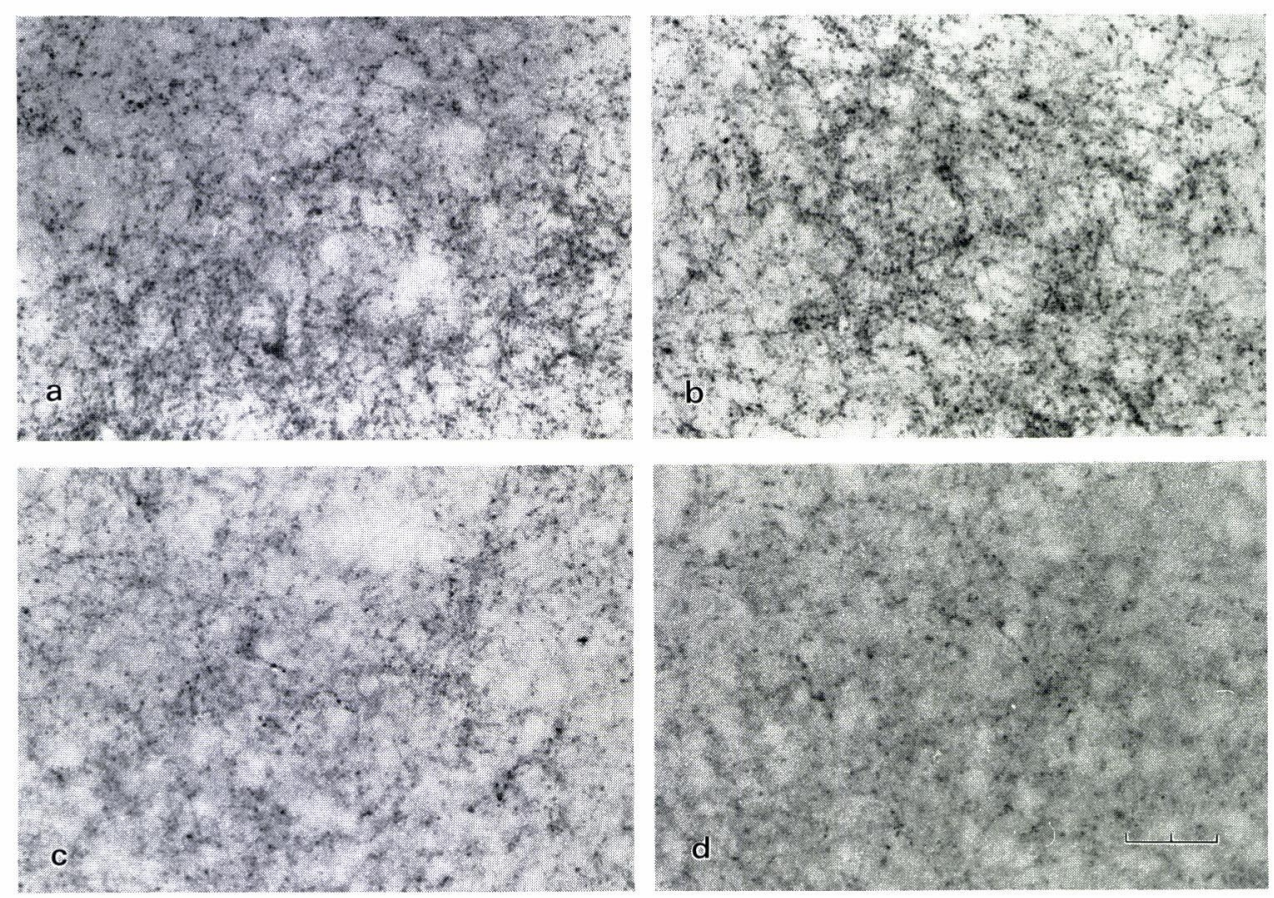

Fig. 6. Light micrographs of VIP immunostaining. Changes in the tinctability of the VIP immunopositive neurons with time.

(a) $6 \mathrm{~s}$ post ischemia, control side, (b) $6 \mathrm{~h}$ post ischemia, ischemic side, (c) $12 \mathrm{~h}$ post ischemia, ischemic side, and (d) 3 days post ischemia, ischemic side. Scale Bar $=20 \mu \mathrm{m}$. There is no significant difference from the control side.

\section{Discussion}

In cerebral infarction in humans, complete ischemia is relatively rare, but incomplete ischemia continuing for a long period is thought to occur relatively frequently. The primary factors in determining the prognosis of cerebral ischemia are time and rate of blood flow, but in cases involving permanent infarct and post ischemic dissolution, morbidity and the course of progression differ, and exhibit complex phases.

As a model of focal cerebral ischemia, we oculuded a rat middle cerebral artery at $1 \mathrm{~h}$, and examined changes due to ischemia in the vasodilative neuropeptides CGRP, SP and VIP in the easily damaged amygdaloid complex.

\section{1) CGRP Immunopositive Neurons}

CGRP is a 37 amino acid peptide with powerful vasodilative effects ${ }^{81}$. In the amygdaloid complex, no CGRP immunopositive cell bodies have been recognized, but CGRP fibrous webs have been extraordinarily abundant. The origin of CGRP fibers in the amygdaloid complex has been confirmed to be localized in the nucleus peripeduncularis ${ }^{9}$.

In this study, the immunotinctability of CGRP immunopositive neurons decreased significantly from $12 \mathrm{~h}$ after ischemia. At $24 \mathrm{~h}$, compared to the control side a nonsignificant rise was seen in the ischemic side, with return to normal levels at 3 days. CGRP concentrations in the blood increased at $6 \mathrm{~h}$, peaked at $12 \mathrm{~h}$, and then steadily declined at $24 \mathrm{~h}$ and 3 days. 
It is suggested that this ischemia is related to a decline in immunotinctability and a rise in CGRP blood levels caused by synaptic release of CGRP from axon terminals. Recovery of both levels to normal within $24 \mathrm{~h}$ to 3 days after ischemia also indicates that CGRP synthesis in the neurons rises.

\section{2) SP Immunopositive Neurons}

Within the amygdaloid complex, SP immunopositive cell bodies were found most often in high density in the area between the central nucleus and the medial nucleus. In other nuclei as well, SP immunopositive fibers have been observed in low to moderate density. It has been proven that some fibers originating from the nucleus peripeduncularis of the amygdaloid complex are both SP and CGRP immunoreactive. Axons of the SP cells in the central nucleus have been shown to pass through the terminal stria and project into the bed nucleus of the terminal stria, hypothalamic lateral nucleus, and lower brain stem ${ }^{10}$.

The immunotinctability of SP immunopositive fibers decreased at 12 and $24 \mathrm{~h}$ and recovered 1 week after ischemia. SP concentration in the blood stream declined from $6 \mathrm{~h}$, reached its nadir at $12 \mathrm{~h}$, and recovered at $24 \mathrm{~h}$ after ischemia. It may be possible that the reduction of SP release into the blood stream as well as the continued decrease in the immunotinctability of positive fibers may be a result of delayed rise in the synthesis of SP due to ischemia.

The SP immunopositive fibers in the amygdaloid complex have been shown to originate from the nucleus peripeduncularis and SP neurons in the amygdaloid complex, and it is possible that SP synthesis ability varies in both areas.

\section{3) VIP Immunopositive Neurons}

VIP is a 28 amino acid peptide with powerful vasodilative properties and has been reported to potentiate the effects of parasympathetic acetylcholine ${ }^{8)}$. VIP immunopositive cell bodies are known to be widely distributed throughout the medial nucleus, periamygdaloid area, and the anterior and posterior lateral nuclei in the amygdaloid complex. VIP immunopositive fibers also exist in the central nucleus in addition to the above areas. Axons of the VIP cells in the amygdaloid body pass through the terminal stria and project into the bed nucleus of the terminal stria, hypothalamus and the lower brain stem ${ }^{11}$. It has been shown that fibers containing VIP are distributed along the smooth muscle cells of the blood vessel walls, and terminate near the smooth muscle cells of the vascular adventitial lining ${ }^{12)}$.

In the present experiment, the immunoreactive intensity of VIP neurons as well as the blood concentration of VIP did not significantly change over the test period. In incomplete $2 \mathrm{~h}$ ischemia utilizing a one sided internal carotid artery ligature in mongolian gerbil mice no change in the tinctability of VIP immunopositive fibers in the cerebral cortex, but $6 \mathrm{~h}$ ischemia remarkably decreased the tinctability ${ }^{13)}$. In our experimental observations: 1) the Wistar rat, which is more highly collateral vascularly developed than the mongolian gerbil, was utilized. 2) A focal ischemia model that occludes the middle cerebral artery for $1 \mathrm{~h}$ was used. 3) The observation area was the amygdaloid complex. The results of the two examinations cannot, therefore, be directly compared. The difference in the sensitivity of the peptidergic neurons and catecholaminergic neurons to ischemia have been studied, but from the results of this study at least, it has been shown that CGRP and SP are more sensitive to ischemia than VIP. Results showing that, among the sensitivities of peptidergic neurons to ischemia, variation by substance are of great interest. This study has demonstrated changes in release of vasodilative agonists in the amygdaloid due to ischemia, but more research on the mechanism of the production of these substances is necessary. 


\section{Acknowledgements}

We thank Eisai Co., Ltd. and Olympus Industries for their cooperation in this study.

\section{References}

1) Graham DI: Hypoxia and vascular disorders. In: Greenfield's Neuropathology, 5th ed, Adams JH, Duchen LW (Eds), Edward Arnold, London, pp 153-268 (1992)

2) Tamura A: Animal model of cerebral ischemia. Shinkei Kenkyu No Shinpo, 35: 73-82 (1991) (in Japanese)

3) Plum F: What causes infarction in ischemic brain?: The Robert Wartenberg Lecture. Neurology, 33: 222-233 (1983)

4) Wieloch T: Neurochemical correlates to selective neuronal vulnerability. Molecular mechanisms of ischemic brain damage. Prog Brain Res, 63: 69-85 (1985)

5) Tamura A, Gotoh $\mathrm{O}$ and Sato K: Focal cerebral infarction in the rat; I. Operative technique and physiological monitorings for chronic model. No To Shinkei, 38: 747-751 (1986) (in Japanese)

6) Tamura A, Gotoh O, Sato K, Nagasima T, Matsutani M, Orii H and Graham DI: Focal cerebral infarction in the rat; II. Neuropathological study and local cerebral blood flow pattern. No To Shinkei, 39: 859-863 (1986) (in Japanese)

7) Paxinos G and Watson C: The Rat Brain in Stereotaxic Coordinates. Academic Press, Australia (1986)

8) Goto K, Kimura $\mathrm{S}$ and Masaki T: Novel endogenous peptides acting on cardiovascular system. Tanpakusitsu Kakusan Koso, 35: 325-339 (1990) (in Japanese)

9) Simada S, Siosaka S, Emson PC, Hillyard CJ, Girgis S, MacIntyre I and Tohyama M: Calcitonin gene-related peptidergic projection from the parabrachial area to the forebrain and diencephalon in the rat: an immunohistochemical analysis. Neuroscience, 16: 607-616 (1985)

10) Tohyama M and Shioya Y: Chemical Neuroanatomy. Kouseisha Press, Japan, pp 295-302 (1987) (in Japanese)

11) Luine VN, Rostene W, Rhodes $\mathbf{J}$ and McEwen BS: Activation of choline acetyltransferase by vasoactive intestinal peptide. J Neurochem, 42: 1131-1134 (1984)

12) Itakura $T$, Okuno $T$, Nakakita $K$, Naka $Y$, Kamei I, Nakai $K$, Imai $H$, Komai $N$, Kimura $H$ and Maeda T: Peptidergic innervation of the cerebral blood vessels-An immunohistochemical study. No To Shinkei, 36: 767-773 (1984) (in Japanese)

13) Ueno M, Itakura $T$, Okuno $T$, Naka $Y$, Nakai $K$, Yokote $H$ and Komai $N$ : Selective vulnerability of peptide-containing neurons in cerebral ischemia; Immunohistochemical study. Noushinkeigeka, 19: 1033-1038 (1991) (in Japanese) 